\title{
The Electrical properties of Sintered Compacts of $\mathrm{BiSnSe}_{2}$
}

\author{
M. M. Abd El-Raheem, M. M. Ibrahim,. \\ A. M. Ahmed and S. A. Ahmed \\ Department of Physics, Faculty of Science, Sohag, Egypt.
}

The prepared samples of $\mathrm{BiSnSe}_{2}$ using cold pressing technique showed semimetallic and semconductor behavior depending on the conditions of sintering. Among the semoconducting behavior, the resistivity is weakly dependent on the ambient temperature which is owed to the hopping mechanism to conduction. Also, the behavior of the electrical properties with the applied electric field and the ambient temperature have been detected and interpritted as due to intergrain and intragrain coupling.

\section{Introduction:}

IV-VI semiconductor such as $\mathrm{Pb} \mathrm{Te}, \mathrm{Pb} \mathrm{Se}, \mathrm{Sn} \mathrm{Se}$, or $\mathrm{Sn}$ Te are strongly degenerated materials with a narrow gap [1]. The characteristic property of these crystals is a very high concentration of vacancies in such materials, there exists a possibility to control the number of vacancies by an isothermal annealing [2]. The electrical conductivity and Seebeck coeffecient of samples with various of ternary compounds in the $\mathrm{SbTe}_{\mathrm{Bi}} \mathrm{Bi}_{2} \mathrm{Te}_{3}$ system show that the transport properties strongly vary with composition and temperature [3].

Number of binary liquid chalcogenide alloys of the system IV - VI hav been found to show semiconductor - metallic transition with the change of composition and temperature, [4]. Sn - Se alloy in the solid state contains two intermediate compounds $\mathrm{Sn} \mathrm{Se}$ and $\mathrm{Sn} \mathrm{Se}_{2}$, both of which melt congreuently, [5].

Semiconductor with a narrow forbidden gap have a high static dielctric constant of the lattice. Which generally consists of a phonon and electron contributions $[6,7]$. However, such materials containing $\mathrm{Bi}$ are expected to possess narrow forbidden gap that is because of the semimetallic behaviour of these materials. In addition, the gapless semiconductor could be observed in $\mathrm{Bi}$ based alloys and could be attributed to overlapping of valence and conduction 
bands [8]. Solid solutions on the basis of narrow layered semiconductors $\mathrm{A}_{2}{ }^{\mathrm{V}}$ $\mathrm{B}_{3}{ }^{\mathrm{VI}}$ (where $\mathrm{A}=\mathrm{Bi} \mathrm{Sb}$ and $\mathrm{B}=\mathrm{Se}, \mathrm{Te}$ ) of tetradymite structure (space group $\mathrm{D}_{3 \mathrm{~d}}^{5}$ ) find applications in the field of thermoelctric devices [9]. Besides, solid solutions formed by the melting of $\mathrm{Bi}_{2} \mathrm{Te}_{3}$ and $\mathrm{Bi}_{2} \mathrm{Se}_{3}$ (two $\mathrm{A}_{2}{ }^{\mathrm{V}} \mathrm{B}_{3}{ }^{\mathrm{VI}}$ binaries) are well known to be the best n-type materials for thermoelectric refrigeration at room temperature, and therefore a great amount of work has been done on these alloys, including different methods of preparation. Also, considerable attention has been focused on glasses of $\mathrm{Bi}$ and Se because of their use in optical and photosensitive devices [10]. The question arise in suggesting the present work was a wondering about the situation of substituting Te by its isomer ( $\mathrm{Se}$ ) in the system to study the physical properties of Bi-Sn-Se ternary alloy, prepared by quite different method as will be discussed latter on.

It was found that thermoelements prepared by sintering having the compositions $\mathrm{Bi}_{0.5} \mathrm{Sb}_{1.5} \mathrm{Te}_{3}$ with 0.05 mass $\% \mathrm{~Pb}$ are $\mathrm{p}$ - type and $\mathrm{Bi}_{2} \mathrm{Te}_{2.7} \mathrm{Se}_{0.3}$ with 0.2 mass $\% \mathrm{~S}$ are n-type [11]. Yokota and Katayama [12] found the p-type $\mathrm{Bi}_{2} \mathrm{Te}_{3}$ compound changes to $\mathrm{n}$ - type after short time of sintering at 400 and $500{ }^{\circ} \mathrm{C}$, respectively. Also, controlling the green density, particle size, time and temperature of sintering was found essential to obtain powder compacts of the system $\mathrm{Bi}_{1-\mathrm{x}} \mathrm{Te}_{\mathrm{x}}$ with controlled physical properties [11].

\section{Experimental Technique:}

The ternary $\mathrm{BiSnSe}_{2}$ cast alloy was prepared by using the traditional melt quench technique. The precursor elements were $99.999 \% \mathrm{Bi}, \mathrm{Sn}$ and $\mathrm{Se}$. The resulted bulk ingot has been grinded thoroughly using an agate mortar and then a $63 \mu \mathrm{m}$ particle size has been obtained using electrical shaker. Samples in powder compact form have been prepared using cold pressing technique.

The current (I)-voltage(V) measurements were carried out in the range $93 \mathrm{~K} \leq \mathrm{T} \leq 393 \mathrm{~K}$ using a conventional series circuit with pressure contact holder under moderate vacuum up to $10^{-3} \mathrm{mmHg}$. The electrical resistivity $\rho$ was measured using the Van der Pauw technique. The $\mathrm{X}$-ray investigation has been carried out using a Philips diffractometer (type 1710) with $\mathrm{Cu}-\mathrm{K}_{\alpha}$ target and graphite monochromator giving a monochromatic beam with wave length $1.5418 \AA$ at $40 \mathrm{kV}$ and $30 \mathrm{~mA}$ with scanning speed of $3.76 \mathrm{deg} / \mathrm{min}$.

The surface microstructure of the tested specimens was examined using a scanning electron microscope type JM - 5300 (Japan). In order to study the surface morphology of a specimen, it must be highly polished and with clean surface.

\section{Results and discussions:}




\subsection{Current density (J) - Electric field (E) Characteristics:}

The J-E characteristics of the green compact of theBiSnSe $\mathrm{S}_{2}$ were traced at different temperatures in the range from 93 to $333 \mathrm{~K}$ are as shown in Fig. (1-a). The characteristics reveal the possibility of Ohmic - nonOhmic transition at all considered temperatures of measurements. It is obvious from Fig. (1-a) that $\mathrm{J}$ increases with increasing $\mathrm{T}$, i.e. the series current can be thermally activated. Also, at a certain applied potential, which can be called as the turn-over potential $(\mathrm{Vt})$. The ratio $\mathrm{dI} / \mathrm{dV}$ increased abruptly indicating that, the asprepared sample of $\mathrm{BiSnSe}_{2}$ can undergo switching.

Similar behaviour could be observed for the compact sintered at 250, 325 and at $400{ }^{\circ} \mathrm{C}$ for different periods of time 5, 10, 20, 320 and $640 \mathrm{~min}$. As shown in Fig. (1-b) for $\mathrm{T}_{\mathrm{s}}=400{ }^{\circ} \mathrm{C}$ and $\mathrm{t}_{\mathrm{s}}=640 \mathrm{~min}$; as an example.

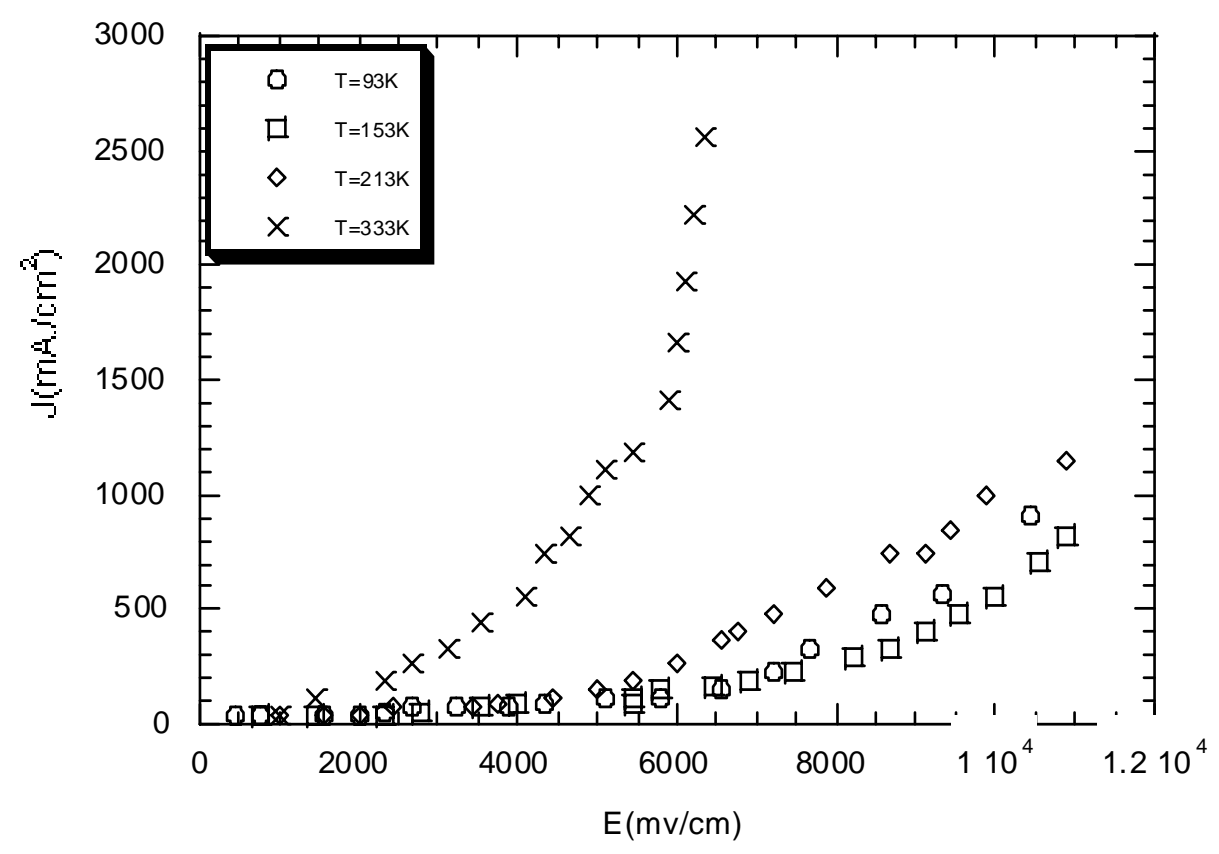

Fig.(1-a):Variation of J vs. E for green compact. 


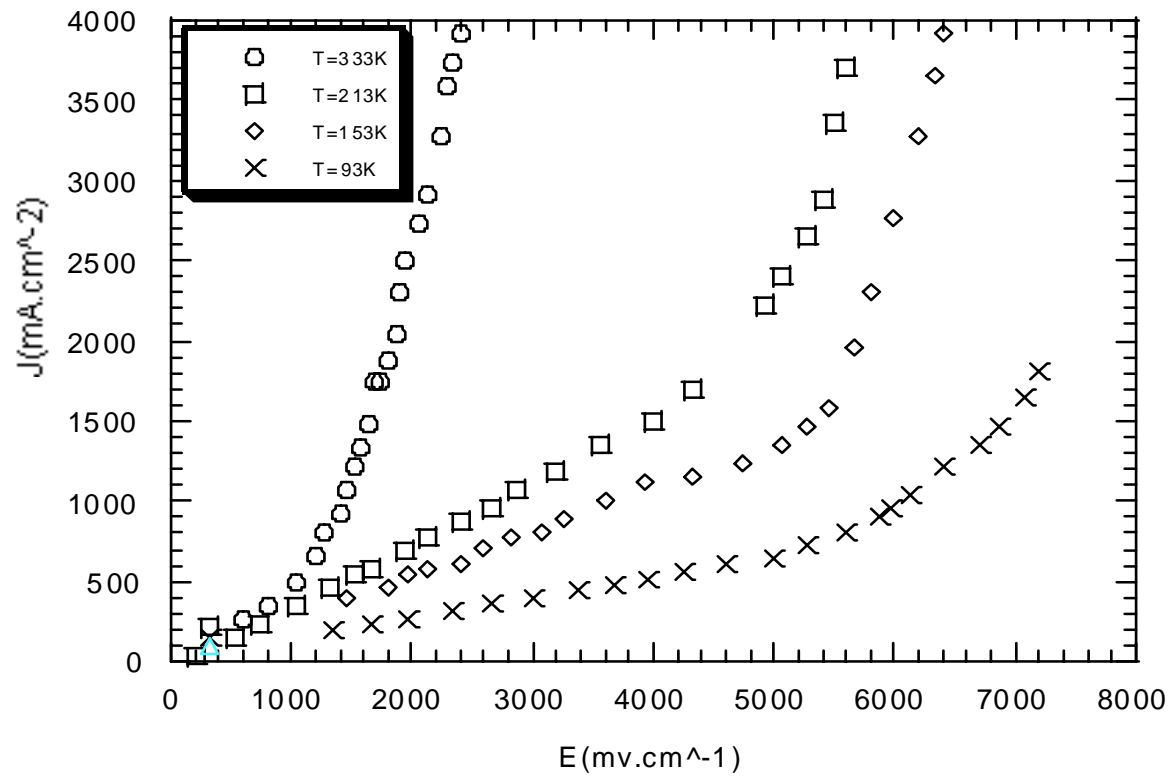

Fig. (1-b): Variation of J vs.E sintered compacts at $T^{\mathrm{s}}=100^{\circ} \mathrm{C}$ ) and $\mathrm{t}^{\mathrm{s}}=640$ min. at different $\mathrm{T}(\mathrm{k})$.

The double logarithmic plots between $\mathrm{J}$ and $\mathrm{E}$ for green and sintered compacts were drawn in Fig. (2) as an example of the case $\mathrm{T}_{\mathrm{s}}=400{ }^{\circ} \mathrm{C}$ for $\mathrm{t}_{\mathrm{s}}=640 \mathrm{~min}$.

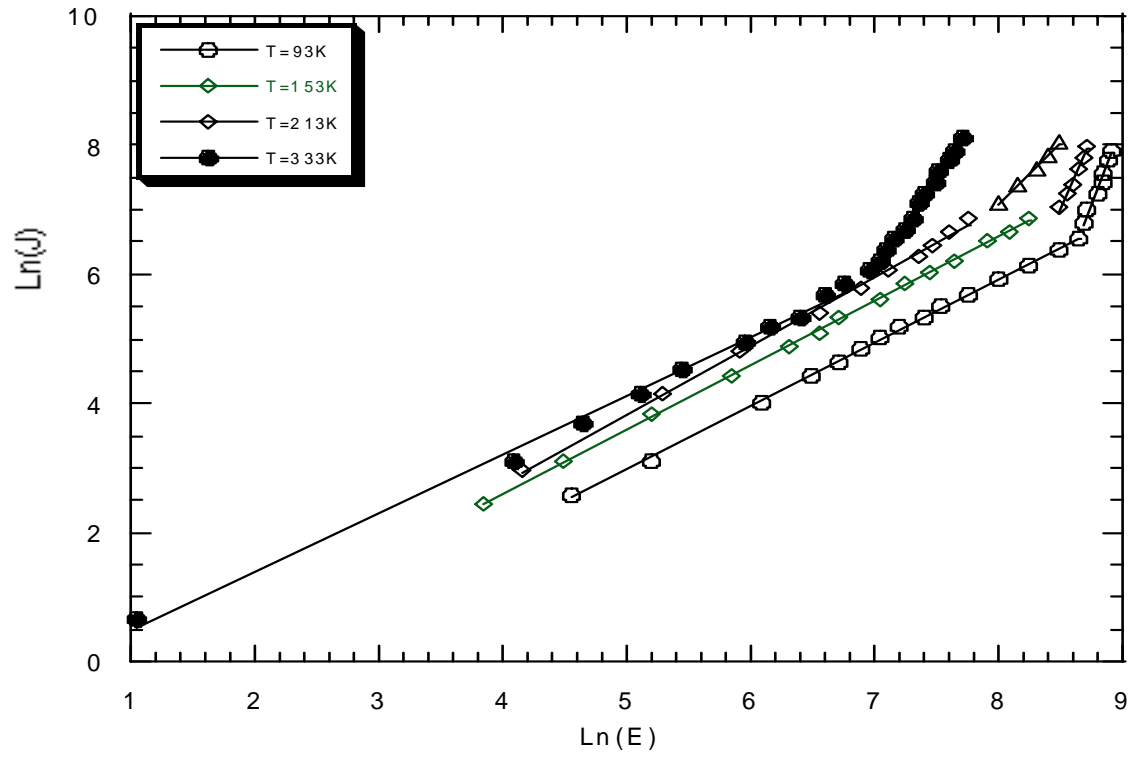

Fig. (2): Variation of $\operatorname{Ln}(\mathrm{J})$ vs. $\operatorname{Ln}(\mathrm{E})$ for compacts sintered at $\left.\mathrm{Ts}=400^{\circ} \mathrm{C}\right)$ and ts $=640$ mins. at different $\mathrm{T}(\mathrm{k})$. 
The $\ln \mathrm{J}-\ln \mathrm{E}$ plots were found to be multistage, each stage is characterized by its own slope $n$ follow the equation $J=C E^{n(T)}$, where $n$ is dependent on both the environmental temperature and the applied field. In addition, every two successive ranges of $\mathrm{J}-\mathrm{E}$ dependence is separated by a transition field Er. The values of $\mathrm{Er}$ and $\mathrm{n}$ were calculated and tabulated in Tables (1\&2) for as-prepared and sintered at $325^{\circ} \mathrm{C}$ and $400{ }^{\circ} \mathrm{C}$, respectively.

Table (1): Variation of the power $n$ and $E_{r}$ with $t_{s}$ at $T_{s}=325{ }^{\circ} \mathrm{C}$.

\begin{tabular}{|c|c|c|c|}
\hline $\mathrm{T}_{\mathrm{am} .(\mathrm{K})}$ & 153 & 213 & 333 \\
\hline \multicolumn{3}{|c|}{ green } \\
\hline$\left(\mathrm{n}_{1}\right)$ & 0.995 & 1.068 & 0906 \\
$\left(\mathrm{n}_{2}\right)$ & 3.628 & 2.749 & 2.5477 \\
\hline $\mathrm{E}_{\mathrm{r}}(\mathrm{v} / \mathrm{cm})$ & 7.230 & 5.380 & 3.3930 \\
\hline \multicolumn{4}{|c|}{$\mathrm{T}_{\mathrm{s}}=20 \mathrm{mins}$} \\
\hline$\left(\mathrm{n}_{1}\right)$ & 1.1606 & 1.2323 & 1.1397 \\
\hline$\left(\mathrm{n}_{2}\right)$ & 2.4853 & 1.5922 & 2.0596 \\
\hline $\mathrm{E}_{\mathrm{r}}(\mathrm{v} / \mathrm{cm})$ & 3.5870 & 3.6370 & 1.3370 \\
\hline
\end{tabular}

Table (2): Variation of the power $n$ and $E_{r}$ with $t_{s}$ at $T_{s}=400{ }^{\circ} \mathrm{C}$.

\begin{tabular}{|c|c|c|c|}
\hline $\mathrm{T}_{\mathrm{am}}(\mathrm{K})$ & 153 & 213 & 333 \\
\hline \multicolumn{4}{|c|}{$\mathrm{T}_{\mathrm{s}}=20$ mins. } \\
\hline$\left(\mathrm{n}_{1}\right)$ & 1.061 & 1.0513 & 1.0183 \\
\hline$\left(\mathrm{n}_{2}\right)$ & 1.264 & 2.348 & 1.1598 \\
\hline $\mathrm{E}_{\mathrm{r}}(\mathrm{V} / \mathrm{cm})$ & 1.401 & 3.101 & 0.785 \\
\hline \multicolumn{4}{|c|}{$\mathrm{T}_{\mathrm{s}}=320$ mins. } \\
\hline$\left(\mathrm{n}_{1}\right)$ & 1.199 & 1.199 & 1.0871 \\
\hline$\left(\mathrm{n}_{2}\right)$ & 2.327 & 1.932 & 2.438 \\
\hline $\mathrm{E}_{\mathrm{r}}(\mathrm{V} / \mathrm{cm})$ & 4.218 & 2.579 \\
\hline \multicolumn{5}{|c|}{$\mathrm{T}_{\mathrm{s}}=640$ mins. } \\
\hline$\left(\mathrm{n}_{1}\right)$ & 1.017 & 1.063 & 0.934 \\
\hline$\left(\mathrm{n}_{2}\right)$ & 4.597 & 2.832 & 2.559 \\
\hline $\mathrm{E}_{\mathrm{r}}(\mathrm{V} / \mathrm{cm})$ & 5.11 & 4.222 & 0.903 \\
\hline
\end{tabular}

At these tables, for green and sintered compacts for 20 min., $\mathrm{n}_{1}$ corresponds to the lowest range of $\mathrm{E}$ and possessed a value near to unity confirming that, at relatively week applied electric field, ohmic conduction behaviour is prevailing in both cases, green and sintered compacts. On the other hand, $n 2$, which correspond to the higher range of $E$, exceeded much the value 
unity confirming that the Ohmic behaviour is no longer valid and the conductivity $\sigma=\mathrm{J} / \mathrm{E}$ became field dependent .

The $\ln \sigma-\mathrm{E}$ is drawn for the green and sintered compacts at the considered temperature and time of sintering. As shown in Fig. (3), the plots of $\ln \sigma(\mathrm{E})$ vs. $\mathrm{E}$ at different ambient temperatures in the range $93 \mathrm{~K} \geq \mathrm{T} \geq 333 \mathrm{~K}$ for sintered compact at $325{ }^{\circ} \mathrm{C}$ for $40 \mathrm{~min}$ and sintered one at $400{ }^{\circ} \mathrm{C}$ for 640 min are linear and may follow the equation [13];

$$
\sigma(\mathrm{E}, \mathrm{T})=\sigma(0, \mathrm{~T}) \exp [\mathrm{e} \mathrm{A}(\mathrm{T}) \mathrm{E} / \mathrm{KT}]
$$

where $\mathrm{E}$ is the applied electric field, $\sigma(0, \mathrm{~T})$ is the field independent conductivity at particular temperature, e is the electronic charge, $\mathrm{A}(\mathrm{T})$ is a temperature dependent parameter having the dimension of length and $\mathrm{K}$ is the Boltzmann's constant.

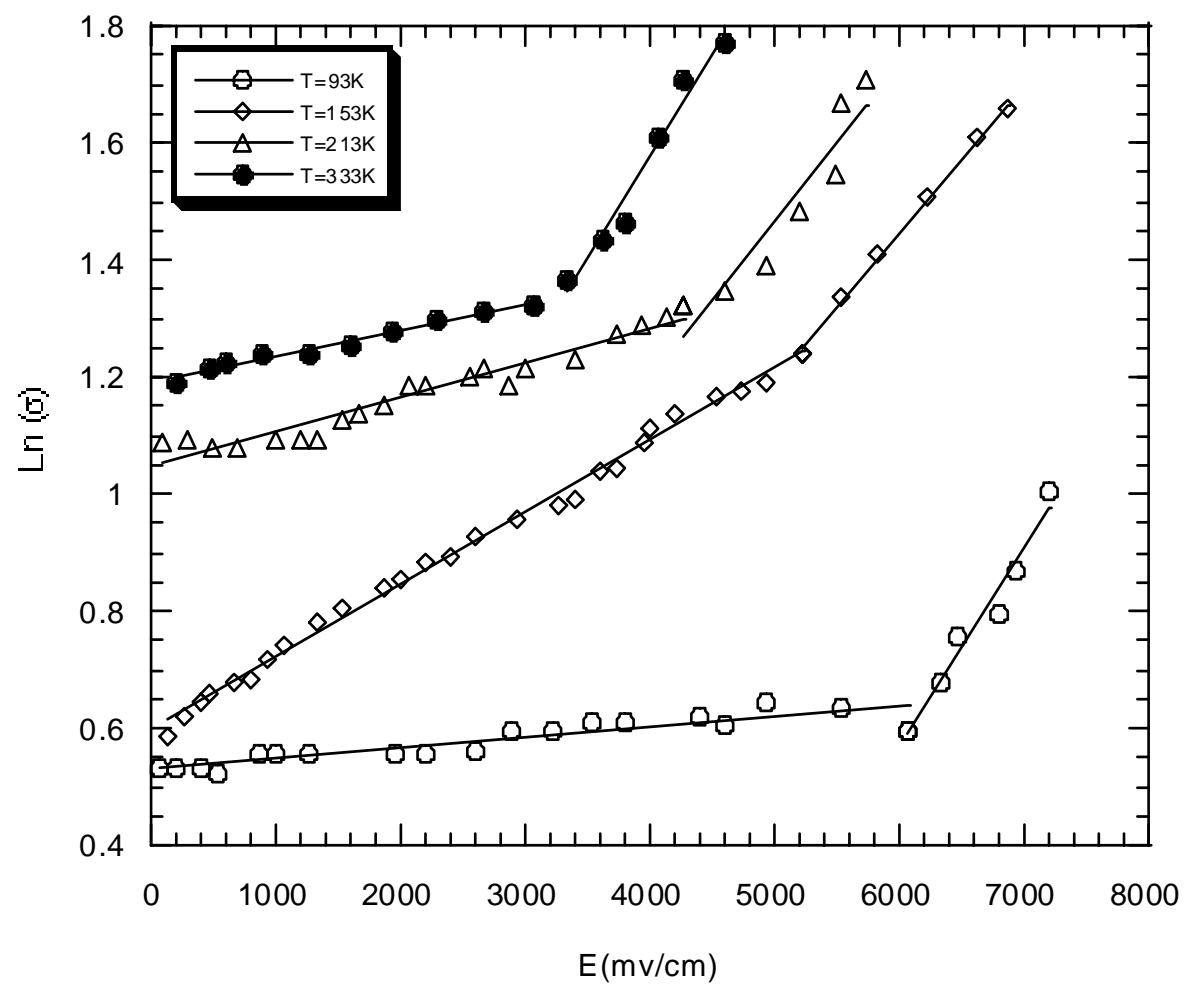

Fig (3-a): Variation of $\operatorname{Ln}(\varepsilon)$ vs. E for sintered compact at $T s=325 \mathrm{C}$ and ts $=40 \mathrm{~min}$. 


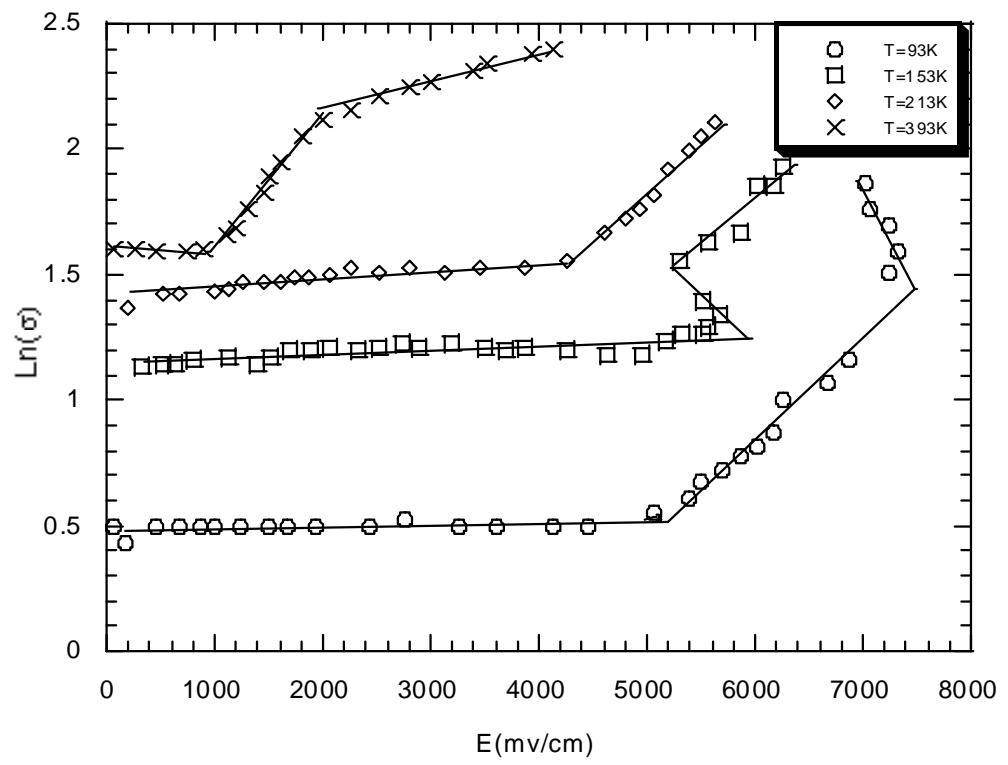

Fig.(3-b):Variation of $\operatorname{Ln}(\sigma)$ vs. $E(\mathrm{mv} / \mathrm{cm})$ for sample sintered at $\mathrm{Ts}=400 \mathrm{C}$ and $\mathrm{ts}=640 \mathrm{mins}$ at different $\mathrm{T}(\mathrm{K})$.

Fig. (3-a) shows that $\sigma$ dependes on the range of E. On the other hand Fig. (3-b) shows another berhaviour, where, the general feature of the considered plot is characterized by whether a weak dependence or entire independency of $\ln \sigma(\mathrm{E})$ on $\mathrm{E}$ which represents the Ohmic behaviour. The highest range of $E$ characterized by multi-feature dependence of $\ln \sigma(E)$ on $E$ that is because of the possibility of the turn-over or switching process as discussed in the former section. However, the most important are those regions characterized by conductivity field enhancement, since it gives the possibility of calculating the parameter $\mathrm{A}(\mathrm{T})$. Further, the field independent conductivity $\sigma$ $(0, T)$ can be determined from the extrapolation of this region. Thus, both $\mathrm{A}(\mathrm{T})$ and $\sigma(0, \mathrm{~T})$ were calculated, at different times of sintering, at particular temperature. The obtained results indicated regular dependence of both $\sigma(0, T)$ and $\mathrm{a}(\mathrm{T})$ on the temperature of measurement. The double logarithmic relations of both $\sigma(0, T)$ and $A(T)$ vs. $T$ were plotted. This was a trial to generalize the temperature dependence of $\sigma(0, \mathrm{~T})$ and $\mathrm{A}(\mathrm{T})$. 


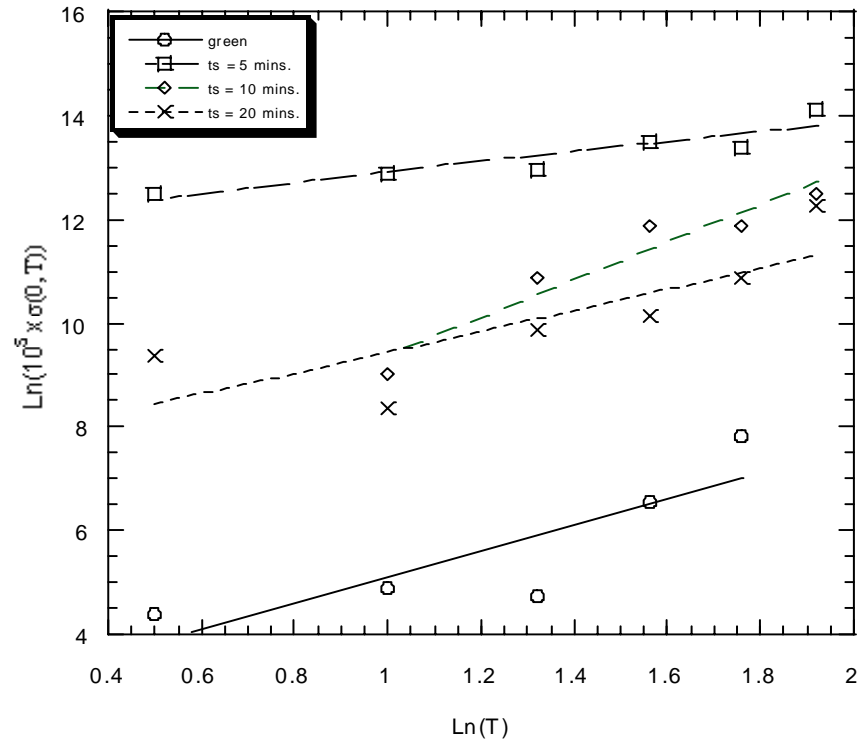

Fig.(4-a): Variation of $\operatorname{Lns}(0, T)$ vs. $\operatorname{Ln}(T)$ for green and sintered sample at $\mathrm{Ts}=325 \mathrm{C}$ at different ts.

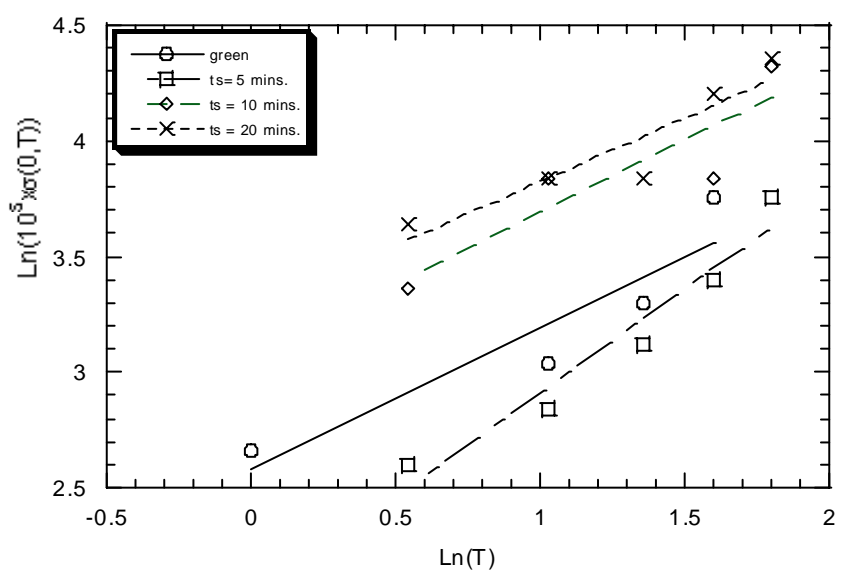

Fig.(4-b).: Variation of $\operatorname{Ln} \sigma(0, T)$ vs. $\operatorname{Ln}(T)$ for green and sintered compacts at $400 \mathrm{C}$ at different ts.

As it is seen in Figs. (4-a\&b), the plots of $\ln \sigma(0, T)$ vs $\ln T$ are linear, suggesting the possibility of describing the dependence in terms of a power equation as:

$$
\sigma(0, \mathrm{~T}) \sim \mathrm{T}^{\mathrm{y}}
$$

Meanwhile, Fig. (5) represents $\ln \mathrm{a}(\mathrm{T})$ vs. $\ln (\mathrm{T})$ suggests the following power equation;

$$
\alpha(T) \sim T \zeta
$$




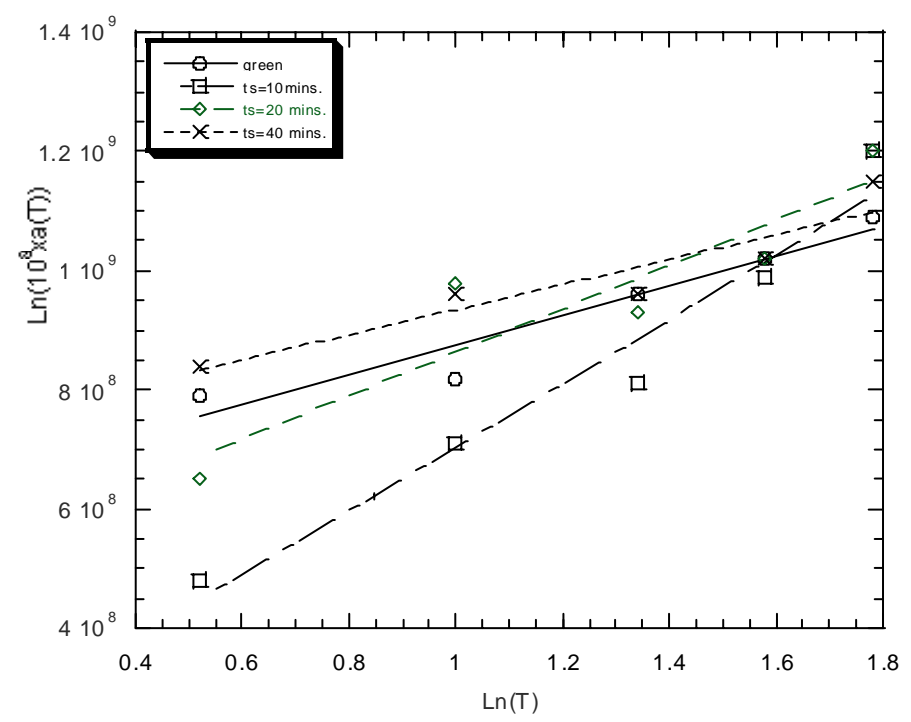

Fig. (5): Variation of $L n a(T)$ vs. $L n(T)$ for green and sintered compacts at $T s=325 \mathrm{C}$ at different ts.

Both the powers $\mathrm{y}$ and $\mathrm{z}$ are calculated and their dependencies on the time of sintering are recorded in Table (3).

Table (3): Variation of $z$ and $y$ with $t_{s}$ and $T_{s}$.

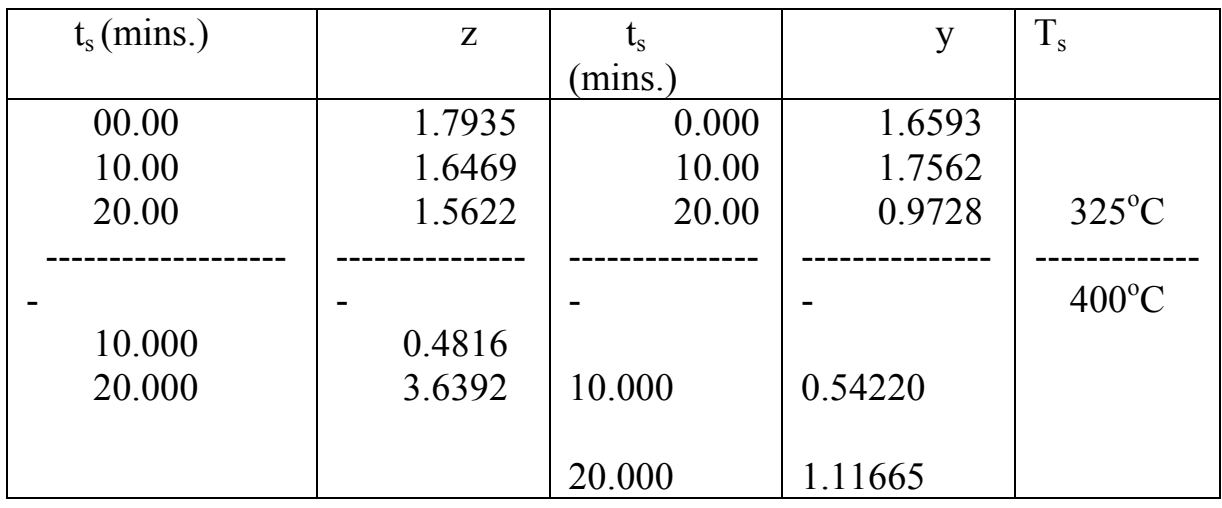

As it is seen in Table (3), the powers y and $z$ have a trend to decrease with increasing the time of sintering at both considered sintering temperatures.

It is clear from Eqn. (1) that the product $\mathrm{A}(\mathrm{T})$.E gives the potential difference of the electrical work required for charge carrier transportation to contribute to the observed electrical conductivity at a particular temperature of measurement. Consequently, the significance of $\mathrm{a}(\mathrm{T})$ can be understood to be 
the distance should a charge carrier travel to contribute to conduction. In case of non-crystalline solids it is acceptable to be related to the hopping distance. In case of the granular materials such as the powder compacts, it is acceptable to be related strongly to the potential barriers due to the boundaries between the grains. However, this explanation seems controversial since, $\mathrm{A}(\mathrm{T})$ was found to increase with increasing $\mathrm{T}$. Therefore, it is more logic to correlate the increase in $\mathrm{A}(\mathrm{T})$ with $\mathrm{T}$ to a corresponding thermal activation of the processes of scattering. In turn, $\mathrm{A}(\mathrm{T})$ should be correlated to the mean free path and the frequency of collision process occurred during the transition of charge carrier from one site to another along the compact dimentions. As it is seen in Fig. (6), the plots of $\ln \sigma(0, T)$ vs $1 / T$ are linear with minus coefficient suggesting the following empirical formula;

$$
\ln \sigma(0, \mathrm{~T})=\mathrm{C} \exp \left[-\Delta \mathrm{E}_{\sigma}(0, \mathrm{~T}) / \mathrm{KT}\right]
$$

where $\mathrm{C}$ is a temperature independent parameter having the significance of the temperature independent zero field electrical conductivity and $\Delta \mathrm{E}$ has the significance of activation energy, i. e. the energy required for thermal activation of $\sigma(0, \mathrm{~T})$.

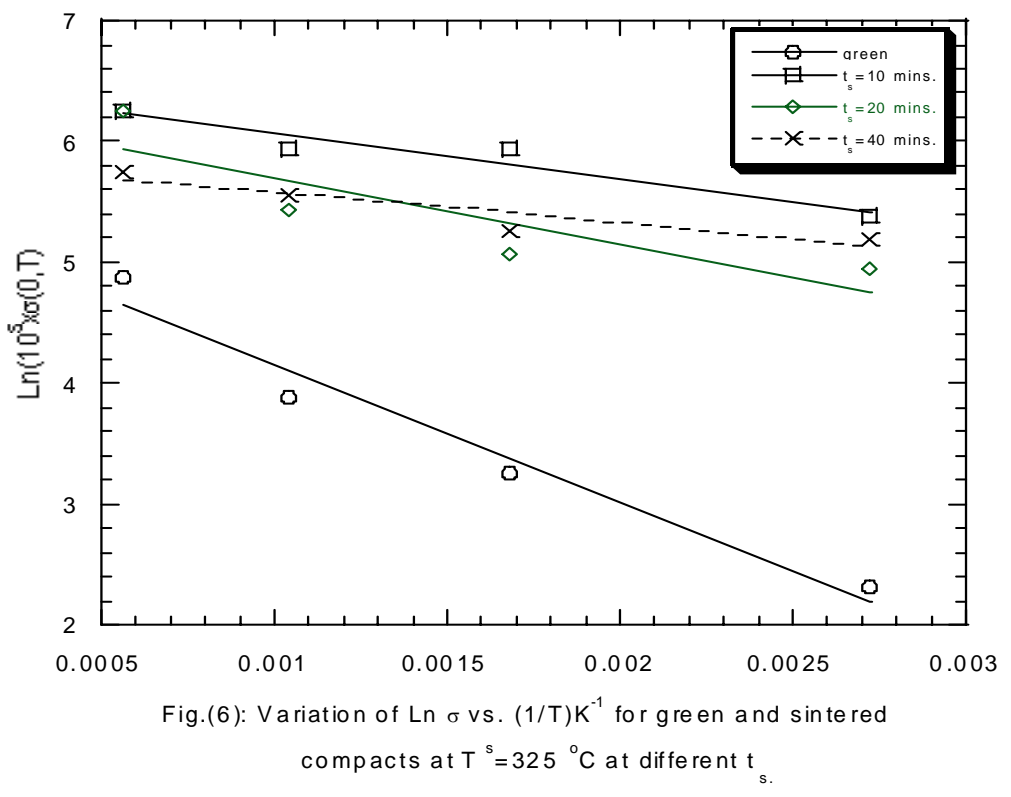


Table (4): Variation of $\Delta \mathrm{E}_{\sigma(0, \mathrm{~T})}$ and $\Delta \mathrm{E}_{\alpha(\mathrm{T})}$ with $\mathrm{t}_{\mathrm{s}}(\mathrm{min})$ and $\mathrm{T}_{\sigma}$.

\begin{tabular}{|c|c|c|c|c|}
\hline $\mathrm{t}_{\mathrm{s}}(\min )$ & $\Delta \mathrm{E}_{\sigma(\mathrm{T})}(\mathrm{e} . \mathrm{v})$ & $\mathrm{t}_{\mathrm{s}}(\min )$ & $\Delta \mathrm{E}_{\mathrm{a}(\mathrm{T})}(\mathrm{e} . \mathrm{v})$ & $\mathrm{T}_{\mathrm{s}}$ \\
\hline 00.00 & 0.02708 & 0.000 & 0.02182 & \\
10.00 & 0.03410 & 10.00 & 0.03623 & \\
20.00 & 0.02506 & 20.00 & 0.01211 & $325^{\circ} \mathrm{C}$ \\
40.00 & 0.01331 & 40.00 & 0.00538 & \\
------- & --------- & -0.000 & 0.00814 & \\
10.000 & 0.00530 & 10.000 & 0.01481 & $400{ }^{\circ} \mathrm{C}$ \\
20.000 & 0.04871 & 20.000 & 0.01823 & \\
40.000 & 0.03092 & 40.000 & \\
\hline
\end{tabular}

As it is seen in Table (4), $\Delta \mathrm{E}_{\sigma}(0, \mathrm{~T})$ decreased with increasing sintering time at $325{ }^{\circ} \mathrm{C}$ except at $\mathrm{t}_{\mathrm{s}}=10$ mons.. Also, at $\mathrm{T}_{\mathrm{s}}=400{ }^{\circ} \mathrm{C}, \Delta \mathrm{E}(0, \mathrm{~T})$ showed the same trend of change with $\mathrm{t}_{\mathrm{s}}$ as the power $\mathrm{z}$ in equ.(3).

On the other hand, it was found that the $\ln \mathrm{A}(\mathrm{T})$ vs. 1 / $\mathrm{T}$ plots were also linear, suggesting similar exponential empirical equation to describe the temperature dependence of $\mathrm{A}(\mathrm{T})$ as follows;

$$
\mathrm{A}(\mathrm{T})=\mathrm{C} \exp \left[-\Delta \mathrm{E}_{\mathrm{a}}(\mathrm{T}) / \mathrm{KT}\right]
$$

where $\mathrm{C}$ is a temperature independent constant representing the value of $\mathrm{A}(\mathrm{T})$ at infinite temperature. $\Delta \mathrm{E}_{\mathrm{a}(\mathrm{T})}$ is the corresponding activation energy having the significance of the energy required for thermal elongation of the distance between two successive sites of the charge carriers as discussed above. As it is seen in Table (4), $\Delta \mathrm{E}_{\mathrm{a}(\mathrm{T})}$, possessed small values and having the same trend with $t_{s}$ as for the power $z$ in Eqn.(3).

The question arises now is, to what extent, $\Delta \mathrm{E}_{\mathrm{a}(\mathrm{T})}$ can be compared to the hopping energy. The answer will be presented latter on.

\subsection{Electrical Resistivity:}

Tracing the temperature dependences of resistivity revealed the possibility of semicondctor, metallic and semiconductor-metallic transition behaviours. This is found to depend on the temperature and time of sintering and also the range of temperature at which the resistivity was measured. The linear scale temperature dependence of the resistivity in the range $183 \mathrm{~K} \leq \mathrm{T} \leq$ $383 \mathrm{~K}$ for the green and sintered for different times at 250,325 and $400{ }^{\circ} \mathrm{C}$ compacts indicated the possibility of prevailing of the three types of behaviours 
as mentioned above. Therefore, it seemed more convenient to separate each behaviour and treat it separately. Fig. (7) shows the double logarithmic relations between the resistivity $(\rho)$ and the temperature of measurement where the behaviour proved to be semimetallic which can be described by the following equation;

$$
\operatorname{Ln}\left(\rho-\rho_{\mathrm{o}}\right)=\alpha \ln \mathrm{T} \quad \text { or } \quad \rho=\rho_{\mathrm{o}}+\mathrm{T}^{\alpha}
$$

where $\rho_{o}$ has the significance of the residual resistivity. As shown in Table (5), $\rho_{\mathrm{o}}$ found to depend on the temperature $\mathrm{T}_{\mathrm{s}}$ as will as $\alpha$.

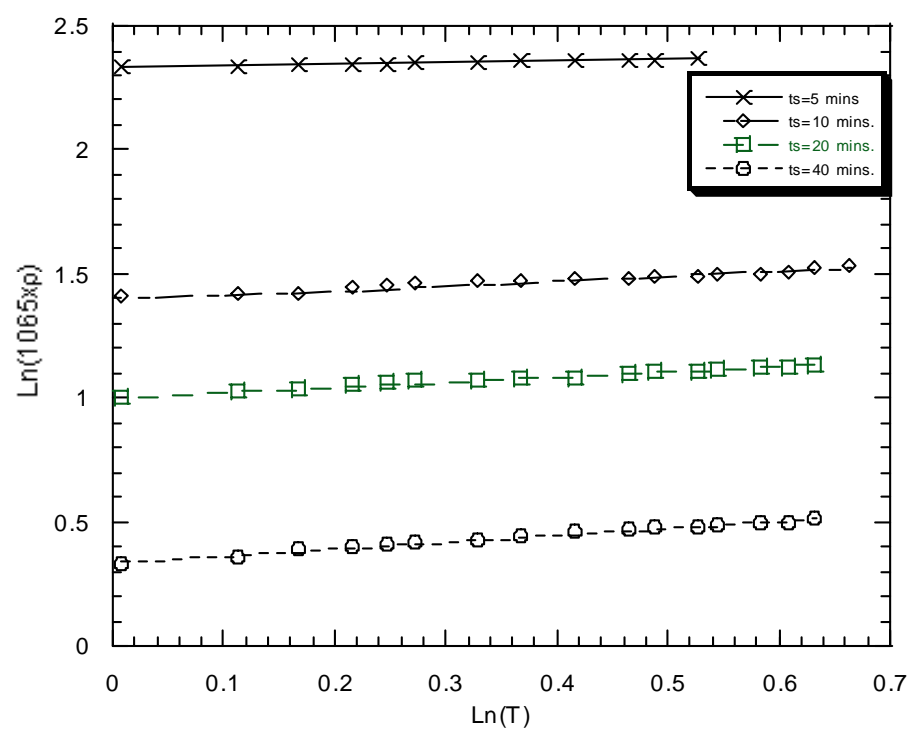

Fig.(7) $\operatorname{Ln}(\rho)$ vs. $\operatorname{Ln}(T)$ for green and sintered compacts at $T s=250 \mathrm{C}$ at different $t$

Table (5): Variation of $\alpha$ and $\rho_{\mathrm{o}}(\Omega . \mathrm{cm})$ with $\mathrm{t}_{\mathrm{s}}$ (mins.) and $\mathrm{T}_{\mathrm{s}}\left({ }^{\circ} \mathrm{C}\right)$.

\begin{tabular}{|c|c|c|c|c|}
\hline $\mathrm{t}_{\mathrm{s}}(\min )$ & $\alpha$ & $\rho$ & $\mathrm{T}_{\mathrm{r}}(\mathrm{K})$ & $\mathrm{T}_{\mathrm{s}}\left({ }^{\circ} \mathrm{C}\right)$ \\
\hline 40.00 & 0.07280 & 10.6579 & ----------- & 250 \\
\hline \multirow{2}{*}{40.00} & 0.01350 & 12.8010 & 244 & 325 \\
\hline \multirow{3}{*}{40.00} & 0.08550 & 8.6167 & ----------- & \\
& 0.13700 & 6.3994 & 245 & \\
& 0.19000 & 4.7803 & 354 & 400 \\
\hline
\end{tabular}

It is seen also in Table (5) that $\alpha$ increases with increasing $\mathrm{T}_{\mathrm{s}}$ (considering the second stage belongs to $\mathrm{T}_{\mathrm{s}}=325{ }^{\circ} \mathrm{C}$ ), whereas, $\rho_{\mathrm{o}}$ behaved inverse to that of $\alpha$. 
Also, it is observed also from Table (5) that the sintered compact at $325{ }^{\circ} \mathrm{C}$ has a metallic behaviour at $40 \mathrm{~min}$ of sintering. Further, Sintering at $400{ }^{\circ} \mathrm{C}$ results in values of $\rho_{\mathrm{o}}$ comparable to those of pure metals as indicated in Table (5). The relation between $\ln \sigma$ and $1 / T$ found to be linear possessing negative sign slopes and following the equation,

$$
\sigma=\sigma_{\mathrm{o}} \exp \left[-\Delta \mathrm{E}_{\sigma} / \mathrm{KT}\right]
$$

The values of the conduction activation energy corresponding to these slopes were as recorded in Table (6). It is clear from Table (6) that $\Delta \mathrm{E}_{\sigma}$ increased by transition from one lower stage to the successive higher one of $\mathrm{T}$, on the other hand, the values of $\Delta \mathrm{E}_{\sigma}$ are small, in the range of $\mathrm{meV}$, so in the basis of the small values of $\Delta \mathrm{E}$, the weak dependence of $\sigma$ on $\mathrm{T}$ can be emphasized.

Table (6): Variation of $\Delta \mathrm{E}_{\sigma}(\mathrm{e} . \mathrm{v}), \sigma_{\mathrm{o}}(\Omega . \mathrm{cm})^{-1}$ and $\mathrm{T}_{\mathrm{r}}(\mathrm{K})$ with $\mathrm{t}_{\mathrm{s}}$ and $\mathrm{T}_{\mathrm{s}}$.

\begin{tabular}{|c|c|c|c|c|c|c|c|c|}
\hline$t_{s}$ (mins.) & $\Delta \mathrm{E}_{\sigma 1}$ (e.v) & $\Delta \mathrm{E}_{\boldsymbol{\sigma} 2}$ (e.v) & $\Delta \mathbf{E}_{\sigma 32}($ e.v) & $\sigma_{0} 1(\Omega . C M)^{-1}$ & 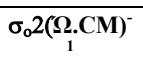 & $\sigma_{\mathrm{or}}(\mathbf{\Omega} . \mathbf{C M})^{-1}$ & $\begin{array}{c}\text { Tr1(K } \\
\text { ) }\end{array}$ & $\begin{array}{c}\text { Tr1(K } \\
\text { ) }\end{array}$ \\
\hline \multicolumn{9}{|c|}{$T_{\mathrm{s}}=250^{\circ} \mathrm{C}$} \\
\hline 0.00 & -0.01470 & -0.03510 & -0.0877 & 284.80 & 728.2 & 4972.7 & 251.60 & 318.15 \\
\hline 80.0 & -0.00166 & -0.00996 & ------- & 8558.0 & 11421 & ------- & 333.33 & ------ \\
\hline \multicolumn{9}{|c|}{$T_{\mathrm{s}}=325^{\circ} \mathrm{C}$} \\
\hline 0.00 & -0.0138 & -0.04250 & -0.1006 & 170.80 & 671.6 & 6353.2 & 243.60 & 299.90 \\
\hline 80.0 & -0.0072 & -------- & ------- & 9041.6 & ------- & ------- & - ------ & -ב-ב-י- \\
\hline
\end{tabular}

Also, it is observed from Table (6) that $\sigma_{0}$ behaved similar to $\Delta \mathrm{E}_{\sigma}$, despite, it possessed small values especially these corresponding to the lowest range of $T$. This is another confirmation of the weak dependence of the electrical conductivity on temperature. This weak dependence of resistivity on temperatures promotes thinking about hopping conduction which was tested in the following. Considering that the measured conductivity $\sigma$ is a sum of $\sigma_{\text {Ext }}$ (band-type conduction) and $\sigma_{\text {hop }}$ (due to hopping conduction within the localized states), Mott [15] proposed the following expression to describe the temperature dependence of the hopping conductivity,

$$
\sigma_{\text {hop }}=\sigma \mathrm{T}^{-1 / 2} \exp \left[-\left(\mathrm{T} / \mathrm{T}_{\mathrm{o}}\right)^{1 / 4}\right]
$$

where

$$
\sigma_{\mathrm{o}}^{2} \sim\left[\mathrm{N}\left(\mathrm{E}_{\mathrm{F}}\right) / 2 \pi \alpha \mathrm{K}\right]\left\{3 \mathrm{e}^{2} v \phi_{\mathrm{o}} / 2\right\}
$$

where $v$ is the Debye frequency $\left(\sim 10^{13} \mathrm{~Hz}\right)$ (Nagels [1980]) and e is the electronic charge and $\phi_{\mathrm{o}}$ is an overlap integral and is of the order of unity.

The density of states $\mathrm{N}\left(\mathrm{E}_{\mathrm{F}}\right)$ at the Fermi level can be calculated on considering the value of $T_{0}$ which represents the slope of the $\ln \left(\sigma \mathrm{T}^{1 / 2}\right) \mathrm{vs} . \mathrm{T}^{-1 / 4}$ 
Since

$$
\mathrm{T}_{\mathrm{o}}=18 \gamma^{2} / \mathrm{K}_{\mathrm{B}} \mathrm{N}\left(\mathrm{E}_{\mathrm{F}}\right)
$$

The parameter $\gamma$ in the above equation represents the coefficient of exponential decay of the localized state and assumed to be $0.124^{\circ} \mathrm{A}^{-1}$ (Fritsche [1974] ). On the other side, the hopping distance can be expressed as follows;

$$
\mathrm{R}=\left\{9 / 8 \pi \gamma \mathrm{K}_{\mathrm{B}} \mathrm{TN}\left(\mathrm{E}_{\mathrm{F}}\right)\right\}^{1 / 4}
$$

and can be calculated at different conditions. Furthermore, the average hopping energy W could be also calculated using the following expression;

$$
\mathrm{W}=3 / 4 \pi \mathrm{R}^{2} \mathrm{~N}\left(\mathrm{E}_{\mathrm{F}}\right)
$$

The linear plots between $\ln \left(\sigma \mathrm{T}^{1 / 2}\right)$ and $\mathrm{T}^{-1 / 4}$ proved the possibility of application of Mott's formula for hopping conductivity. The corresponding Mott's parameters are calculated and then recorded in Table (7).

As seen in Table (7), three ranges of dependence of $\sigma \mathrm{T}^{1 / 2}$ on $\mathrm{T}^{-1 / 4}$ could be observed in case of green compacts. Consequently, three values could be calculated for each of the Mott parameters. Those parameters were calculated first for three green compacts which were post - sintered at the considered three temperatures 250, 325, and $400{ }^{\circ} \mathrm{C}$. The slight deviation in different Mott parameters from compact to another indicates the sampling effect which could be ignored any how. However, this very slight differences proved good control in the conditions of preparation.

As shown in Table (7), the values of $\sigma_{0}$ belonging to the three green compacts decreases with transition from lower to successive higher range of $\mathrm{T}$. This proved more thermal activation of the electrical conductivity with increasing the range of temperature, i.e the hopping conduction is thermally assisted. Meanwhile, $T_{0}$ increased with transition from a lower to a successive higher range of $\mathrm{T}$, this confirms again thermally activated conduction or thermally assessed hopping conduction. On the other hand, values of $N\left(E_{F}\right)$ decrease with elevating the range of $\mathrm{T}$, such behaviour confirms the possibility of contribution of band to band (extended states) conduction at elevated temperature ranges. Besides, the hopping distance $\mathrm{R}$, possessed values ranging from $10^{-7}$ to $10^{-6} \mathrm{~cm}$ and increase with increasing $\mathrm{T}$. These values of $\mathrm{R}$ are very small with respect to the average particle size of the originally compacted powder. Also, they are very small with respect to the inter particle distance. This might indicate that hopping occurs mainly between the localized states in the grains themselvse i.e intragrain hopping. The contribution of hopping between the particles themselves which can be called as intergrain hopping (hopping beween grain boundaries i.e between the particles costituting the compact) can not be ignored, however, its role seems weak. On the other hand, 
the average hopping energy $\mathrm{W}$ for green compacts possessed very small values, and its value increased with elevating $\mathrm{T}$.

Table (7): Variation of Mott's parameters with $\mathrm{T}_{\mathrm{s}}\left({ }^{\circ} \mathrm{C}\right.$ ) and $\mathrm{t}_{\mathrm{s}}$ (mins.)

\begin{tabular}{|lllllll|}
\hline \multicolumn{1}{|c}{$\mathrm{T}_{\mathrm{o}}(\mathrm{K})$} & $\mathrm{N}\left(\mathrm{E}_{\mathrm{F}}\right) \mathrm{ev}^{-1} \mathrm{~cm}^{-3}$ & $\sigma_{\mathrm{o}} \times 10^{4}(\Omega \mathrm{cm})^{-1}$ & $\mathrm{R}(\mathrm{cm})$ & $\mathrm{x} 10^{3} \mathrm{ev}$ & $\mathrm{t}_{\mathrm{s}} /(\mathrm{mins})$. & $\mathrm{T}_{\mathrm{s}}\left({ }^{\mathrm{o}} \mathrm{C}\right)$ \\
\hline 181801.0 & & & & & & green \\
0 & $2.19 \mathrm{E}+21$ & 3.540 & $6.25 \mathrm{E}-7$ & & & \\
1637102. & $2.43 \mathrm{E}+20$ & 1.180 & $1.08 \mathrm{E}-6$ & & & \\
0 & $2.19 \mathrm{E}+19$ & 0.354 & $1.98 \mathrm{E}-6$ & & & \\
18165763 & & & & & & \\
\hline 7179.0 & $2.55 \mathrm{E}+22$ & 17.82 & $2.79 \mathrm{E}-7$ & 0.199 & 80 & green \\
41945 & $9.5 \mathrm{E}+21$ & 7.37 & $4.33 \mathrm{E}-7$ & 0.309 & & \\
\hline 178201 & $2.23 \mathrm{E}+21$ & 3.580 & $6.22 \mathrm{E}-7$ & 0.443 & & 325 \\
5008854 & $7.95 \mathrm{E}+19$ & 0.675 & $1.43 \mathrm{E}-6$ & 1.021 & & \\
50172321 & $7.94 \mathrm{E}+18$ & 0.213 & $2.55 \mathrm{E}-6$ & 1.816 & & \\
\hline 26839 & $1.48 \mathrm{E}+22$ & 9.220 & $3.88 \mathrm{E}-7$ & 0.376 & 80 & \\
56216 & $7.08 \mathrm{E}+21$ & 6.370 & $4.66 \mathrm{E}-8$ & 0.332 & & \\
\hline
\end{tabular}

Considering that this energy is that equired for hopping to occur, these small values reveal easy hopping. This is a consequences of the relatively small values obtained for the hopping distance $\mathrm{R}$. Regarding the values of $\mathrm{R}$ and $\mathrm{W}$ in Table (7) it is obvious that $\mathrm{W}$ is directly proportional to R. Meanwhile, the values obtained for $\mathrm{W}$ are about one order of magnitude smaller with respect to the values obtained for $\Delta \mathrm{E}_{\alpha(\mathrm{T})}$ recorded in Table (4). This may reveal that not only intergrain but intragrain hopping is contributing to the total hopping process occuring in the sample.

As mentioned before, sintering at $250^{\circ} \mathrm{C}$ was characterized by semimetallic behaviour except at 80 mins. of sintering. Despite of this unique time of sintering at which hopping conduction was prevailing, the different Mott parameters were calculated and then recorded in Table (7). As it is seen, the process of sintering at this temperature for this period of time, resulted in promption of the extrapolated conductivity $\sigma_{0}$ by about one order of magnitude. The corresponding value for $T_{o}$ decreased while $N\left(E_{F}\right)$ increased by about one order of magnitude. The hopping distance possessed values in the ranges of $10^{-7}$ at both ranges of $T$. Consequently, the average hopping energy possessed relatively small values compared to the green condition. At $325^{\circ} \mathrm{C}$ of sintering, hopping condition was prevailing and the corresponding Mott parameters are as seen in Table (7). At $T_{\mathrm{s}}=325{ }^{\circ} \mathrm{C}$, the characteristic temperature $\mathrm{T}_{\mathrm{o}}$ possessed values in the ranges $10^{5}-10^{4}$ where hopping conduction was prevailing. The density of localized states $\mathrm{N}\left(\mathrm{E}_{\mathrm{F}}\right)$ has values in the range of $10^{22} \mathrm{~cm}^{-3} \mathrm{eV}^{-1}$. The 
hopping distance $\mathrm{R}$ possessed values in the range $10^{-7} \mathrm{~cm}$ and the general trend of $\mathrm{R}$ is to decrease with prolongating $t_{s}$.

As a whole, the general trend is that, $\mathrm{R}$ increased with decreasing $\mathrm{T}_{\mathrm{s}}$. $\mathrm{W}$ changed parallel to $\mathrm{R}$ since both decreased with prolongating $t_{\mathrm{s}}$. The effect of sintering time at $\mathrm{T}_{\mathrm{s}}=250{ }^{\circ} \mathrm{C}$ and $400{ }^{\circ} \mathrm{C}$ could be revealed by plotting the normalized change in the resistivity $\varepsilon$ as a function of $t_{s}$ as shown in Fig. (8).

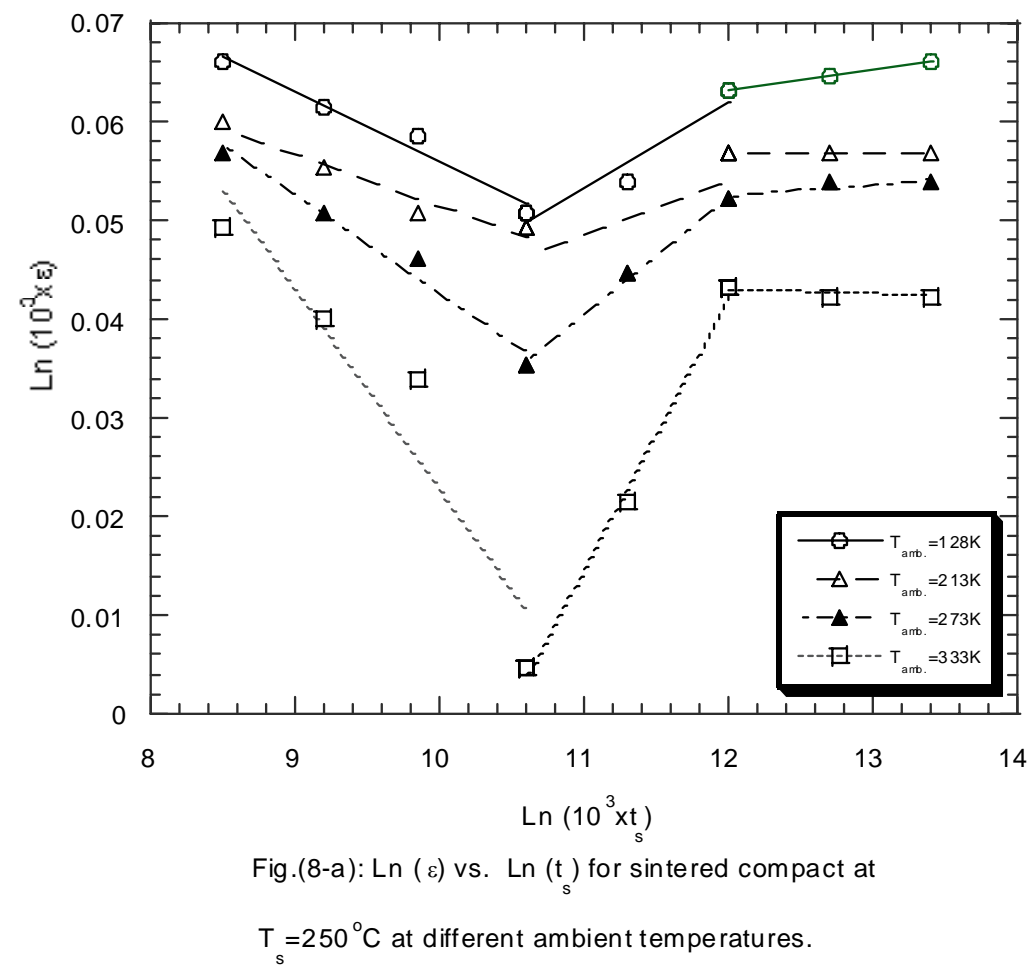




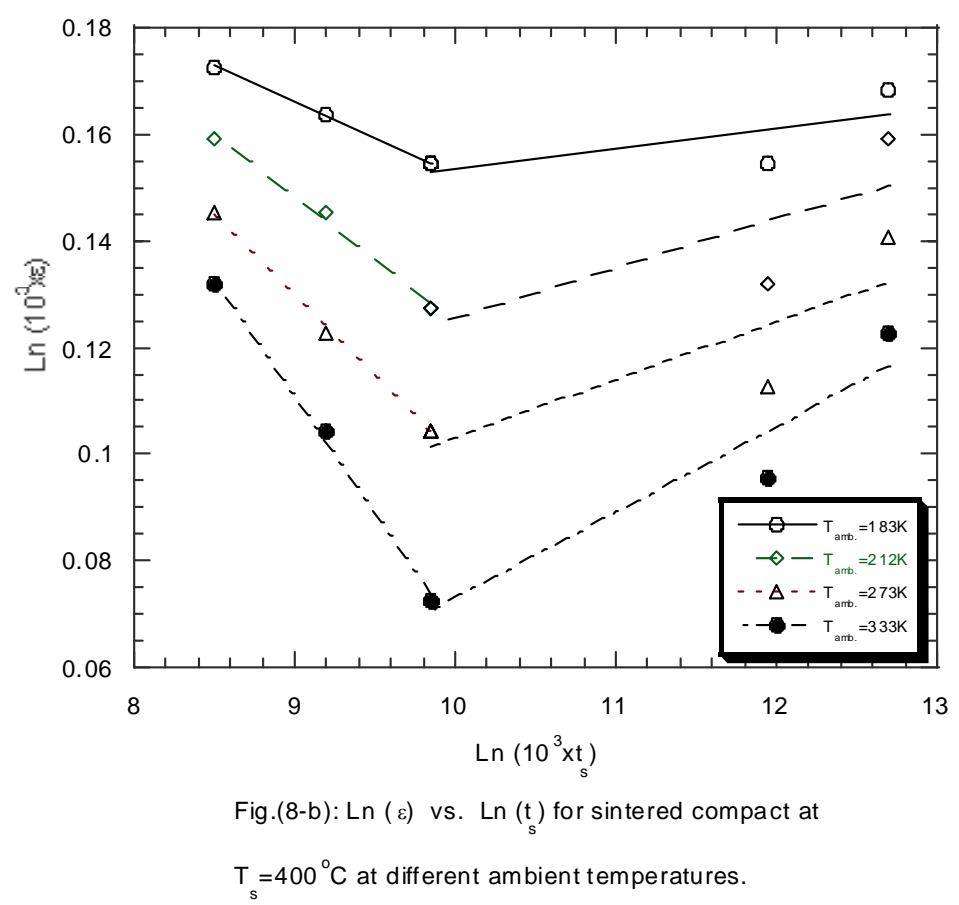

As it is seen in the later figure, the first small period of sintering is characterized by a decrease in $\varepsilon$ by prolongating $t_{s}$. However, it is worthmentioning that the normalized change in resistivity $\varepsilon=\left(\rho_{\mathrm{ts}}-\rho_{\mathrm{o}}\right) / \rho_{\mathrm{o}}$ where, $\rho_{\mathrm{o}}$ is the resistivity of the green compact and $\rho_{\mathrm{ts}}$ is that measured at particular time of sintering. As it is shown that $\varepsilon$ possessed minimum value at $t_{s}$ $=40$, and 20 at $\mathrm{T}_{\mathrm{s}}=250{ }^{\circ} \mathrm{C}$ and $400{ }^{\circ} \mathrm{C}$, respectively. Above these times, $\varepsilon$ increased again with further prolongating $\mathrm{t}_{\mathrm{s}}$. Another minima could be observed at $t_{\mathrm{s}} 160$ mins. For $\mathrm{T}_{\mathrm{s}}=400{ }^{\circ} \mathrm{C}$.

The linear dependence of $\ln \varepsilon$ on $\ln t_{s}$ is found to follow the power equation;

$$
\varepsilon=\mathrm{Ct}^{ \pm \alpha(\mathrm{T})}
$$

As formally mentioned that the power $\alpha$ possessed wether plus or minus sign depending on wether $\varepsilon$ increases or decreases with prolongating $t_{s}$. Values calculated for $\alpha$ are recorded in Table (8). As it is seen at $\mathrm{T}_{\mathrm{s}}=250{ }^{\circ} \mathrm{C}$, three values were recorded for $\alpha$ which are corresponding to the three linear parts of each of the double logarithmic plots. It is obvious that $\alpha_{1}$ and $\alpha_{2}$ increases with increasing the ambient temperature, whereas, $\alpha_{3}$ decreases with elevating T. At $\mathrm{T}_{\mathrm{s}}=325^{\circ} \mathrm{C}$, only one range of $\ln \varepsilon$ vs $\ln \mathrm{t}_{\mathrm{s}}$ is drawn, so only one value could be recorded for $\alpha$. 
It is found that $\alpha$ increased with increasing T. At $400{ }^{\circ} \mathrm{C}$, two values $\alpha_{1}$ and $\alpha_{2}$ could be recorded at each temperature. It is clear from Table (8) that $\alpha_{1}$ increased negatively with elevating T. Also, $\alpha_{2}$ increased with elevating T.

Table (8): Variation of $\alpha$ with $\mathrm{T}$ and $\mathrm{T}_{\mathrm{s}}$.

\begin{tabular}{|c|c|c|c|c|}
\hline $\mathrm{T}(\mathrm{K})$ & $\alpha 1$ & $\alpha 2$ & $\alpha 3$ & $\mathrm{~T}_{\mathrm{s}}\left({ }^{\mathrm{o}} \mathrm{C}\right)$ \\
\hline 183 & -0.00637 & 0.00827 & 0.000549 & \\
\hline 213 & -0.00697 & 0.00916 & 0.000479 & \\
\hline 243 & -0.00788 & 0.01042 & 0.000396 & \\
\hline 273 & -0.00918 & 0.01217 & 0.000220 & 250 \\
\hline 303 & -0.01082 & 0.01430 & 0.000072 & \\
\hline 333 & -0.01313 & 0.01727 & -0.000280 & \\
\hline 363 & -0.01667 & 0.02196 & -0.000919 & \\
\hline 383 & -0.02036 & 0.02690 & -0.001550 & \\
\hline \multicolumn{5}{|l|}{---- } \\
\hline 183 & 0.00591 & ---------- & ------------ & \\
\hline 213 & 0.00614 & ---------- & ------------ & \\
\hline 243 & 0.00686 & ---------- & ------------ & \\
\hline 273 & 0.00812 & & & -- \\
\hline \multicolumn{5}{|l|}{325} \\
\hline 303 & 0.01045 & ----------- & ------------ & \\
\hline 333 & 0.01307 & ---------- & ------------ & \\
\hline 363 & 0.01732 & ---------- & ------------- & \\
\hline 383 & 0.02161 & ---------- & ------------ & \\
\hline \multicolumn{5}{|l|}{---- } \\
\hline 183 & -0.00974 & 0.02154 & ------------ & \\
\hline 213 & -0.01072 & 0.02240 & ------------- & \\
\hline 243 & -0.01260 & 0.02412 & ------------ & \\
\hline 273 & -0.01507 & & & ---------- \\
\hline \multicolumn{5}{|l|}{400} \\
\hline 303 & -0.01782 & 0.02767 & ------------- & \\
\hline 333 & -0.02210 & 0.03230 & ------------- & \\
\hline 363 & -0.02904 & 0.03752 & ------------ & \\
\hline 383 & -0.03620 & 0.04534 & ------------ & \\
\hline
\end{tabular}

The obtained values for the power $\alpha$ are not comparable with those known for the different mechanisms contribute to the processes of material transport due to the process of sintering using equation;

$$
\varepsilon=\mathrm{C} \mathrm{t}^{\mathrm{m}}
$$

suggested by Johnson and Cutler [16]. The discrepancy lie in, first, the power $\mathrm{m}$ does not possess minus sign except in case of dilation instead of shrinkage. Second, the values recorded for the power $\mathrm{m}$ in Eqn. (14) possess relatively 
high values compared with those obtained for $\alpha$. For the sake of reminiscence, the value of $m$ depends mainly on the process of material transport and filling the pores between the particles and depends also on the contact between the initial grains. First of all, it has to be mentioned that, the prepared ternary is of a layer structure type and the role of filling the pores by transport materials from the original grain is whether absent or at least very weak. Therefore, contribution to the change in resistivity with the time of sintering can be considered to be mainly due to, formation of chemical bonds especially in case of the metallic behaviour and intergrain or intragrain hopping especially in case of semiconductor behaviour. However, it is believed that, the shape of the grain boundaries and link strength between the grains and the grain boundary distribution can contribute to a dominant role. The sign of $\alpha$ being plus or minus, reveals wether $\rho_{s}$ increases or decreases with prolongating $t_{s}$. It is a matter depends on the consequence of the contribution of the above mentioned parameters to $\rho_{\mathrm{s}}$.

\section{Conclusion:}

Because of both semimetallic and semiconductor behaviour, the electrical conductivity could not be enhanced thermally at all. However, most of the temperature enhancement of the zero - field conductivity was attributed to a corresponding enhancement in the charge carrier concentration. On the other hand, the charactristic length was found to be also enhancing with $T$. That is because of the enhancement of the scattering processes by temperature. Where the behavior was that of semiconductors, the values obtained for conduction activation energy were found to be very small confirming weak dependence of resistivity on temperature. This recommended the thought of the hopping mechanism to conduction. The small values obtained for the hopping length confirm the domination of intragrain hopping, despite the role of intergrain hopping can not be ignored. The small values obtained for the hopping energy can be regarded to the small values obtained for the hopping length (easy hopping), however, both $\mathrm{R}$ and $\mathrm{W}$ in direct proportionality. Besides, the discrepancy between the values obtained for the hopping energy (W) and those obtained for $\Delta \mathrm{E}_{\mathrm{a}(\mathrm{T})}$ confirms the contribution of both intergrain and intragrain hopping to the total hopping process of conduction. However, because of the different complicated factors influencing the product of the sintering process, there were no explicit roles to control the influence of both the time and temperature of sintering on the different Mott parameters.

The normalized change in resistivity with the time of sintering could be generalized in the eq.(13) at the three temperatures considered for sintering. Meanwhile, the power of eq.(13) was found to change sequentially with the temperature of measurement despite it seemed having the possibility wither 
minus or plus sign. However, the values obtained for the power of eq.(13) were not comparable with those known for the different mechanisms mechanisms contribute to material transport due to the process of sintering as suggested by Johnson and Cutler [1963]. The discripancy attributed to the layer structure so, the change in resistivity is not due to material transport but, the initiated chemical bond and both the inter and intragrain hopping can play the dominant roles of conduction.

\section{References}

1. Nimtz G., Schlicht B., and Dornhaus R., Narrow Gap Semiconductors, Springer, Berlin (1983).

2. Story T., Acta Phys Pol. A 92, 663(1997).

3. (Xi - Song Zhou, Yuan Deng, Ce - Wen Nan and Yuan Huo Lin. Journal of alloys and compounds volume, 352, p328 (2003).

4. Situlina O. V., Glazov V. M. : Akad. Nauk. SSSR Chem. 167, 587 (1969).

5. Massalski T. B., Okamoto H., Subramanian P. R. and Kacprzak L. : Binary Alloys Phase Diagram ( ASM international, Ohio, (1992) 2ed ed.

6. Rudolph R., Krgger H., Fellmuth B. and Herrmann R., Phys. Status Solidi (b), 102, 295(1980).

7. Z. Zhang, X. Sun, M.S. Dresselhaus, J. Y. Ying and J. Heremans, J. Phys. Rev. B61, p4850 (2000).

8. Ibrahim M. M., Indian Journal of Pure \& Applied Physic, 18, 242(1980)

9. Birkholz U.: Thermoelektrische Bauelemente, in Amorphe und polykristalline Halbleiter, ed. W. HEYWANG, Berlin (1984).

10. Bates C. W. Jr and England L, Appl Phys Lett, 14, 390 (1969).

11. Ibrahim M. M., Afify N., Hafiz M. M. Mahmoud M. A., Powder Metallugy International vool. 20, no. 6, (1988).

12. Yokota K., Katayama S.: Effect of the Heat Treatment On The Electrical Properties Of $\mathrm{Bi}_{2} \mathrm{Te}_{3}$. Technology Reports Of Kansai University (1975) [16].

13. Marshall, J.M. and Miller, J.R., Phil. Mag. 27, 1151(1973).

14. Kulbachinskii V. A., Inoue M., Sasaki M., Negishi H., Gao W. X., Takase K., and Giman Y., Phus. Rev. B Vol. 50, No. 23, 16921 (1994).

15. Mott N. F. : Philos. Mag. 24, 1 (1971).

16. Jonson D. L. and Cutler I. B., J. Am. Ceram. Soc., 46, 541(1963).

17. Kulbachinskii V. A., Negishi H., Sasaki M., Giman Y., Inoue M., Lostak P., and Horak J., Phys. Stat. Soli.(b) 199, 505(1997). 